\title{
Occurrence and recovery of small-sized plastic debris from a Brazilian beach: characterization, recycling, and mechanical analysis
}

Felipe Luis Palombini ${ }^{a}, *$, Renan Demori ${ }^{b}$, Mariana Kuhl Cidade ${ }^{c}$, Wilson Kindlein Junior ${ }^{d}$, Jocelise Jacques de Jacques ${ }^{e}$

a Graduate Program in Design - PGDesign, Federal University of Rio Grande do Sul - UFRGS, Av. Osvaldo Aranha 99/607, 90035-190, Porto Alegre, RS, Brazil

b Chemistry Institute, IQ/UFRGS, Av. Bento Gonçalves 9500, 91501-970, Porto Alegre, RS, Brazil

c Department of Industrial Design, Federal University of Santa Maria - UFSM, Av. Roraima, no 1000, Prédio 40, 97105-900, Santa Maria, RS, Brazil

d Department of Materials - DEMAT/UFRGS, Av. Osvaldo Aranha 99/604, 90035-190, Porto Alegre, RS, Brazil

e Department of Design and Graphic Expression - DEG/UFRGS, Rua Sarmento Leite 320/506, 90050-170, Porto Alegre, RS, Brazil

* Corresponding author: felipe.palombini@ufrgs.br

\section{Abstract}

Small-sized plastic debris are an increasing global concern, particularly in environmental protected areas. Consequently, tourism-based economy of poor coastal regions is also impaired. Nevertheless, little interest has been shown about recycling approaches of such materials, mostly because of the natural degradation of polymers on these conditions. This research presents the report of the occurrence of plastic debris nearby Lençóis Maranhenses National Park, on the northeast Brazilian coast, aiming to provide a feasible method for recycling. We collected more than 80 samples from the sediment and classified them via FT-IR. Degraded polypropylene samples were selected for blending with virgin material using different concentration rates, and were mechanically tested. Tensile testing results suggest that $5 \%$ recycled material concentration mixture has suitable mechanical properties on the elastic regime for applications on new parts. Our findings show that particular interest should be addressed on the recovery of commodity plastic debris from environmental protected areas.

Keywords: mechanical properties; polypropylene; microplastics; sediment; marine ecosystem; sustainability. 


\title{
1. Introduction
}

\begin{abstract}
The ubiquitous presence of polymers and its extensive use in multiple industries lead to an increasing concern about their disposal and recovery (Azapagic et al. 2003; Thompson et al. 2009; Eyerer 2010). While less than 30\% of generated plastic waste is recycled in Europe (PlasticsEurope 2016) and no more than 10\% in the USA (US Environmental Protection Agency 2016), the recycling rates tend to be even lower in developing countries with incipient waste management systems, such as Brazil (Colling et al. 2016; Palombini et al. 2017).
\end{abstract}

Environmental contamination of small-sized polymer waste is an emerging global concern and can be considered a key topic for sustainability research, particularly in marine ecosystems (Thompson et al. 2009; Andrady 2011; Koelmans et al. 2014; Law and Thompson 2014). Despite direct harm to several species, such as seabirds, fishes, turtles and whales (Tanaka et al. 2013; Crawford and Quinn 2017a; Andrady 2017), small plastic debris also impacts on several stakeholders, such as the shipping, fishing and tourism industry (Sheavly and Register 2007; Jang et al. 2014; Laglbauer et al. 2014; Avio et al. 2017). For instance, places of key importance in ecosystems' preservation, such as national parks, are created as areas of environmental protection besides having a significant contribution to the local economy (Begon et al. 2006; Medeiros and Young 2011). Therefore, polymer debris in marine ecosystems can be considered a holistic and sustainability issue due to its effect on economic (Derraik 2002), social (Browne 2015) and environmental (Cole et al. 2011) spheres.

Macro-, meso- and microplastics are terms related to small fragments of plastic waste that enter in marine environments and are categorized according to their size and origin (Gregory and Andrady 2004; Cole et al. 2011; Andrady 2017). A broad range of particle size classifications for plastic debris is found in the literature, thus making it difficult to compare different studies (Van Cauwenberghe et al. 2015; Andrady 2017). For instance, Gregory and Andrady (2004) used the definition of macro-, meso-, and microlitter for fragments of up to 10-15 cm, in the range 5-10 mm, and <500 $\mu \mathrm{m}$, respectively. More recently, the European MSFD technical subgroup on Marine Litter (MSFD GES Technical Subgroup on Marine Litter 2013) proposed a unified, size-based nomenclature of macro- (>2.5 $\mathrm{cm})$, meso- $(0.5-2.5 \mathrm{~cm})$, and microplastic $(1 \mu \mathrm{m}-5 \mathrm{~mm})$. Still, microplastic remained almost a common term in the literature (Andrady 2017). As for its origin, polymeric debris can be divided into primary and secondary nature. Primary microplastics are manufactured in different sizes for several direct applications, from exfoliant in personal care products to virgin pellets in the molding of plastic products (da Costa et al. 2017; Andrady 2017). Secondary microplastics are the majority source of microplastics and correspond to small fragments which result from the breakdown of larger plastic parts (Cole et al. 2011; Avio et al. 2017).

Despite the major impact of plastics debris in marine environments, its recycling remains a little-explored issue (Pietrelli et al. 2017), mostly due to difficulties in collecting, separating and characterizing samples for further recovery (Eerkes-Medrano et al. 2015; Andrady 2017; Sharma and Chatterjee 2017). Therefore, recent studies have also been investigating this issue with aims to standardize methods for macro- and microplastics extraction in locations such as sediment (Van Cauwenberghe et al. 2015; Besley et al. 2017), and fresh and seawater (EerkesMedrano et al. 2015; Horton et al. 2017), as well as characterizing and analyzing their distribution (Graca et al. 2017; Mai et al. 2018). In addition, the characteristics of polymeric chemical bonds that confer plastics their interesting manufacturing properties also make them susceptible to degradation, consequently losing their mechanical properties (Crawford and Quinn 2017b). For instance, among the commodity polymers that are frequently found as debris in marine environments is polypropylene (PP) (Avio et al. 2017), which is liable to chain degradation from exposure to UV light (Niaounakis 2017a), as well as oxidation at high temperatures and abrasion from rocks and sand (Crawford and Quinn 2017b). Despite those abiotic factors, biotic circumstances also contribute to PP degradation, such as specific microorganisms (Cacciari et al. 1993; Janda 2015) and fungi (Muenmee et al. 2015). 
The main objective of this research is to disclose the occurrence of small-sized plastic debris found in a fishing village nearby Lençóis Maranhenses National Park (LMNP), in northeast Brazil - a tourist seashore environment with significant importance to the local economy. Likewise, this paper follows a qualitative approach to characterize the plastic samples, in ways to propose their recovery by recycling. Due to the lack of literature data on the present issue, we present a preliminary profile of polymeric residues most commonly found in that coast area, through the characterization of the types of sediment polymer resins, via infrared spectroscopy. Afterward, we proposed the recycling of PP samples, which were selected due to its typical greater likelihood to degrade under marine ecosystem conditions. Samples with different concentration rates of recycled PP were then blended and mechanically analyzed with tensile testing in order to compare their mechanical properties with those of virgin PP. Finally, the mechanical tests results were discussed and compared with the literature, with aims to provide a reference for the recovery of small-sized polymer waste.

\section{Materials and Methods}

We performed the characterization and analyzed the recovery possibilities of small polymer debris found on the sediment of a fishing village beach, nearby LMNP (MA, Northeast Brazil), by means of recycling and mechanical testing. The analysis aimed a qualitative characterization of types of polymer resins most commonly found, as well as the perform of recycling and mechanical testing procedures.

\subsection{Materials}

88 samples were collected randomly on the surface of the sediment and analyzed according to their size and weight. Collection was carried out manually and no sand sieving was used. The process intended to present an overview of the types of resins commonly found in the area, instead of assessing the relative amount of debris in the sediment. Therefore, no statistical analysis of surface and relative volume of material per quantity of sand was performed.

Resin types of samples were identified via infrared spectroscopy. Polypropylene (PP) samples were selected for a recycling procedure due to the resin's naturally greater oxidation from marine-related conditions, such as UV radiation, which can affect its properties (Gijsman et al. 1999; Azapagic et al. 2003; Andrady 2011, 2017), despite its recent increasing demand (Crawford and Quinn 2017b). After identification, the collected PP samples were blended with $\mathrm{H}$ 503, an additivated PP homopolymer used for general purposes, with a melt flow rate of $3.5 \mathrm{~g} / 10$ min (Braskem ${ }^{\circledR} \mathrm{S} / \mathrm{A}$, Triunfo, RS, Brazil), in different concentrations for mechanical tests.

\subsection{Procedures}

\subsubsection{Fourier Transform Infrared Spectroscopy (FT-IR)}

Collected samples were analyzed via Fourier Transform Infrared Spectroscopy (FT-IR), for the identification of constituent polymer resins. Spectrum 100 (PerkinElmer ${ }^{\circledR}$, Waltham, MA, USA) equipment was used in the FT-IR analyses by attenuated total reflectance mode (ART FT-IR), with a resolution of $4 \mathrm{~cm}^{-1}$ under 16 scans in the region between 4000 and $600 \mathrm{~cm}^{-1}$, in combination with a polymer library.

\subsubsection{Recycling, mixturing, and injection molding}

Polypropylene samples were used for recycling and mechanical analysis based on its high natural degradation in marine environments, such as with heat and sunlight (Crawford and Quinn 2017b). In order to propose a simplified, feasible way of mechanically recovering plastic debris, a manual grinding was used in the recycling process. Therefore, the polypropylene samples were ground into approximately 2-3 $\mathrm{mm}$ diameter particles, compatible in 
size to the virgin PP pellets of H 503. Still, several collected PP samples already presented a relatively small size for the purpose, on a millimeter scale.

Electronic analytical balance AUW-220D (Shimadzu ${ }^{\circledR}$ Corp., Kyoto, Japan) was used for measuring different mixture concentrations of ground recycled PP ( $\mathrm{PPP}$ ) and virgin PP (VPP). To verify the variability in mechanical performance of samples with the increasing content of rPP, three concentration ratios were used: 5\%rPP-95\%vPP; 10\%rPP$90 \% \mathrm{vPP}$; and $15 \% \mathrm{rPP}-85 \% \mathrm{vPP}$.

All materials were dried in hot-air-oven at $80^{\circ} \mathrm{C}$ overnight. The aliquots of rPP added to vPP were physically mixed and then subjected to injection molding. For each mixture concentration, ten ASTM D638-10 Type V specimens were prepared with Haake Minijet II (Thermo Fisher ${ }^{\circledR}$ Scientific Inc., Waltham, MA USA) micro-injection molding machine. In addition to mixture samples, ten control specimens with $100 \% \mathrm{vPP}$ were injected, for comparison. Injection molding parameters are seen in Table 1.

Table 1. Injection molding parameters.

\begin{tabular}{ll}
\hline Melting temperature & $220{ }^{\circ} \mathrm{C}$ \\
Mold temperature & $60{ }^{\circ} \mathrm{C}$ \\
Injection pressure/post pressure & $400 / 380$ bar \\
Injection time/post pressure time & $2 \mathrm{~s} / 4 \mathrm{~s}$ \\
\hline
\end{tabular}

\subsubsection{Tensile testing}

Mechanical performance of the injected specimens was analyzed and compared via a tensile test, by ASTM D63810. EZ-LX series (Shimadzu ${ }^{\circledR}$ Corp., Kyoto, Japan) tensile testing machine was used at speed of $100 \mathrm{~mm} / \mathrm{min}$, along with Trapezium X (Shimadzu ${ }^{\circledR}$ Corp., Kyoto, Japan) software.

\section{Results and Discussion}

\subsection{Sample characterization}

Table 2 summarizes the FT-IR characterization results, divided into five main resin types. The majority of collected samples was characterized as high- or low-density polyethylene (HDPE and LDPE), followed by polypropylene (PP). and ethylene-vinyl acetate copolymer (EVA). Almost 7\% of samples were classified as some type of thermoplastic elastomer (TPE). The apparent aspect of collected samples is shown in Fig. 1.

Table 2. Polymer resin identification, number $(\mathrm{N})$ and relative amount $(\mathrm{R})$ of samples, average mean size $(\bar{D})$ and weight $(\mathrm{M})$.

\begin{tabular}{lcccc}
\hline Polymer identification & N & $\mathbf{R}(\%)$ & $\overline{\mathbf{D}}$ (mm) & M (g) \\
\hline Polypropylene (PP) & 22 & 25.0 & $9.58 \pm 6.24$ & $0.164 \pm 0.109$ \\
Low-density polyethylene (LDPE) & 18 & 20.5 & $10.15 \pm 6.89$ & $0.177 \pm 0.122$ \\
High-density polyethylene (HDPE) & 39 & 44.3 & $15.92 \pm 9.69$ & $0.288 \pm 0.165$ \\
Ethylene-vinyl acetate copolymer (EVA) & 3 & 3.4 & $15.67 \pm 3.21$ & $0.271 \pm 0.066$ \\
Thermoplastic elastomers (TPE) & 6 & 6.8 & $15.51 \pm 6.41$ & $0.309 \pm 0.130$ \\
\hline
\end{tabular}




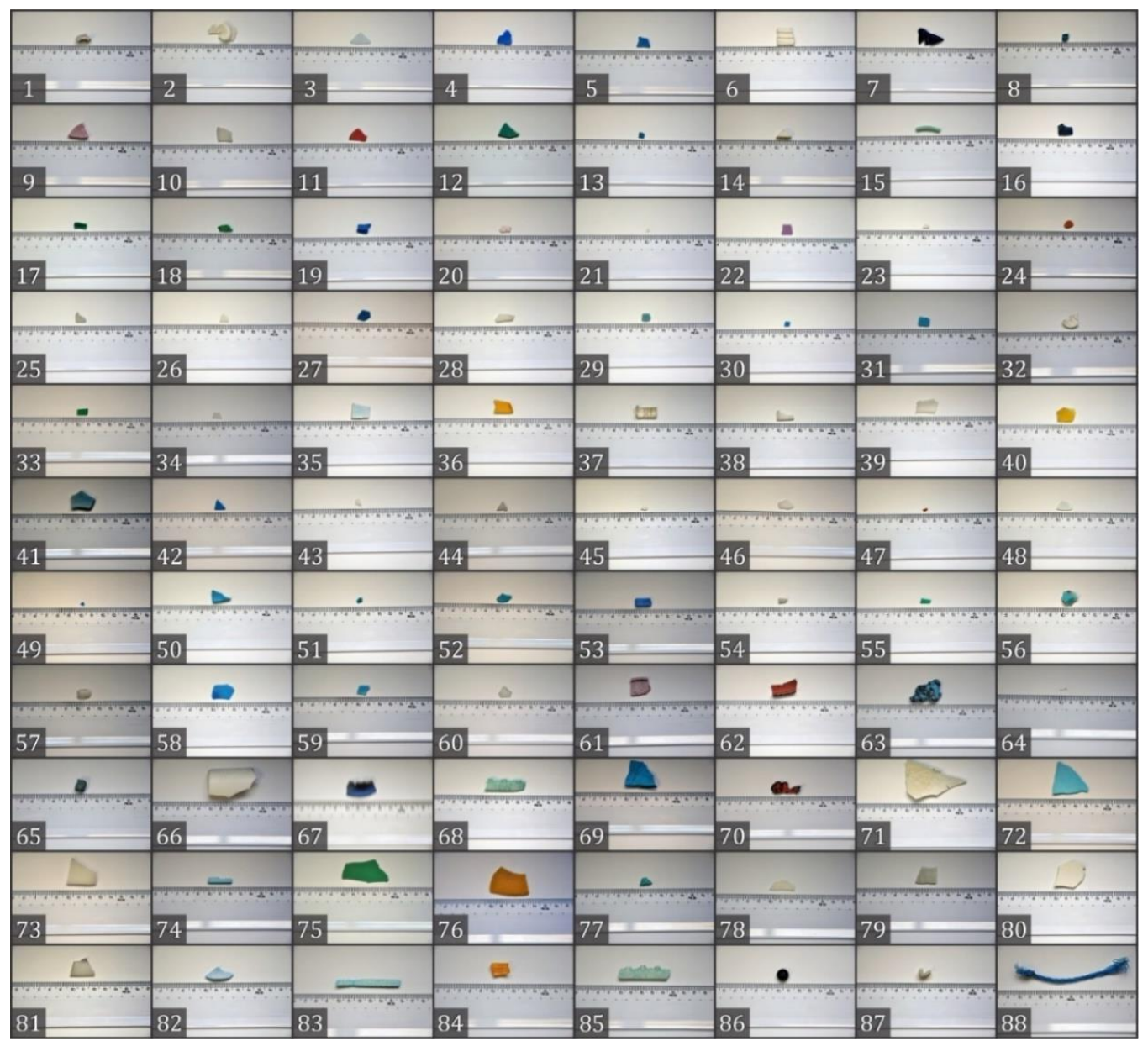

Fig. 1. Apparent aspect of collected plastic debris samples with a ruler (centimeters), collected on the beach of a fishing village, nearby Lençóis Maranhenses National Park, northeast Brazil.

In a global scale compilation analysis, Geyer et al. (2017) estimate the annual primary production and primary waste generation of the most common polymer types. Among the six main commodity resins (PET, HDPE, PVC, LDPE, PP, PS) authors found that $24 \%$ of production and $25 \%$ of waste generation belongs to PP, in weight, in 2015. LDPE corresponded to $23 \%$ and $26 \%$, in production and waste generation, respectively, as well as $19 \%$ for HDPE in both groups. In gross values, $81 \%$ of the PP primary production in weight was generated as primary waste, during the period. As for LDPE and HDPE, $89 \%$ and $77 \%$ of the amount of primary production was generated as residue, in weight, respectively (Plastics Europe 2016; Geyer et al. 2017). That comparison also shows the recovery potential of commodity resins, since the quantity of primary plastic waste generated almost corresponds to that of its production. Even without a statistical approach for collecting, our sampling revealed a similar relative count result to the global production estimation, contributing to the relationship between global plastic waste and marine environment debris (Avio et al. 2017).

Fig. 2 presents the resulting FT-IR transmittance spectra for each identified resin, where the X-axis represents the wavenumber in $\mathrm{cm}^{-1}$. Each resin spectrum is compared to that of a standard commercial material from the equipment library, which indicates the most likely material for that spectrum. The top spectrum represents the analyzed, collected sample and the bottom one corresponds to the library material. 

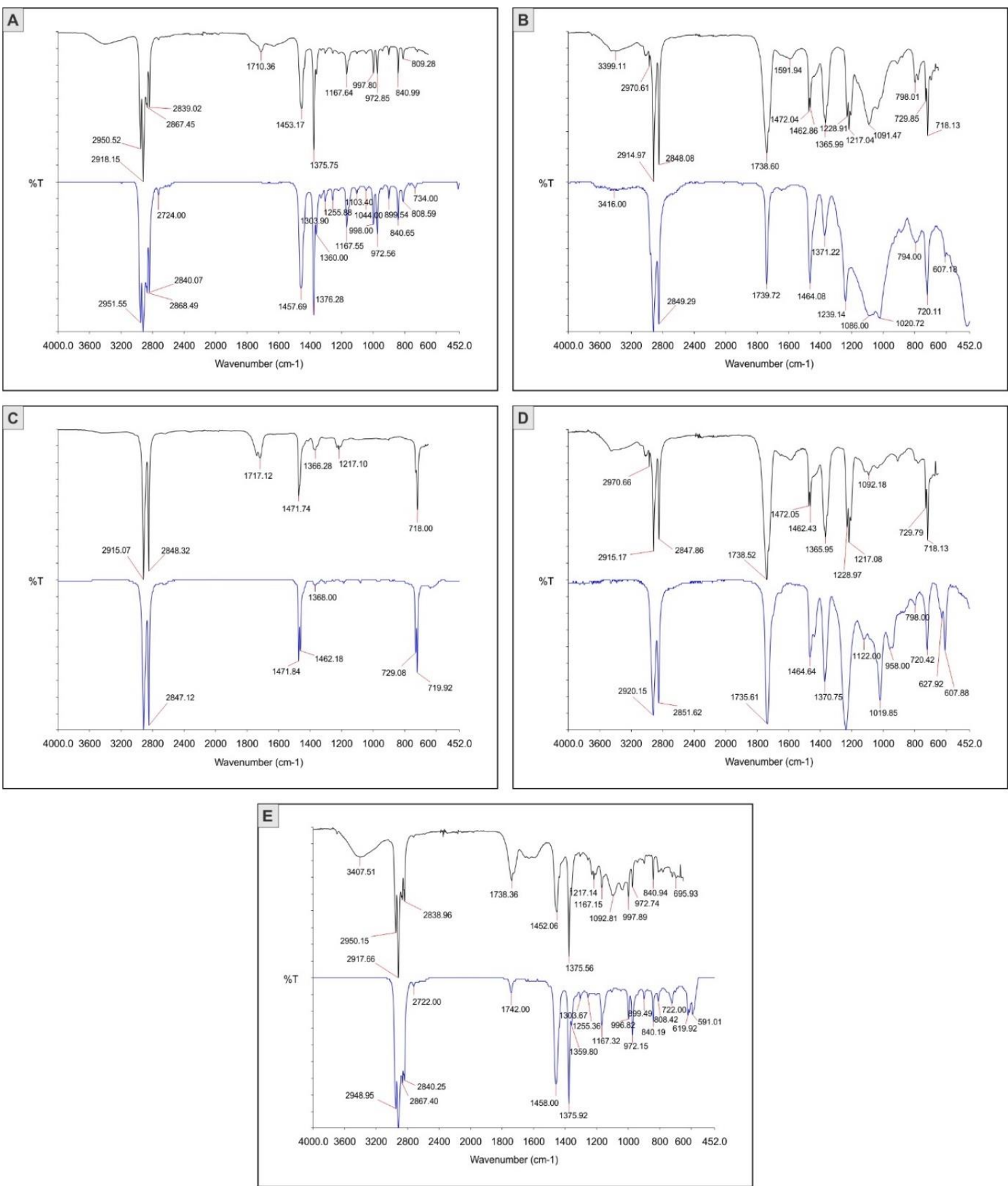

Fig. 2. Examples of FT-IR spectra characterizing the collected samples as: (A) polypropylene, (B) low-density polyethylene, (C) high-density polyethylene, (D) ethylene-vinyl acetate copolymer, and (E) thermoplastic elastomers. The top spectrum represents the analyzed sample and the bottom one corresponds to the library's standard material.

The analyzed and compared spectra of polypropylene, low-density polyethylene, high-density polyethylene, ethylene-vinyl acetate copolymer, and thermoplastic elastomers are shown on Fig. 2 A, B, C, D, and E, respectively. Regarding the spectra $A$, the formation of a peak is noted in the region at $1710 \mathrm{~cm}-1$, related to a carbonyl group associated with PP chain degradation (Marsich et al. 2017). The formation of carbonyl groups occurred by photooxidation of the material subjected to the weather conditions. Additionally, this result demonstrates a level of degradation of the rPP sample collected.

\subsection{Tensile testing}

Tensile test results for the mixture concentrations are seen in Fig. 3, and compared with virgin material. The average 
elastic modulus (Fig. 3A) of the 5\% recycled PP (rPP) resulted in a slight increase of approximately $4 \%$, compared with virgin PP (VPP). On the other hand, higher blend concentrations of $10 \%$ and $15 \%$ resulted in an average decrease of $18 \%$ and $13 \%$, respectively. This variance can be directly related to the degradation and content ratio of the rPP samples. Adding rPP to the mixture decreases the overall molecular weight, thus inducing a reduction in the elastic modulus; nevertheless, this effect can also be compensated by the increase of crystallinity, thus leading to the range of the results (Scott 1999; La Mantia 2002). A similar behavior is seen in the tensile stress at yield (Fig. $3 \mathrm{~B})$, with the $5 \%$ rPP samples resulting in a $6 \%$ increase, compared to VPP. Likewise, the recycled PP showed an average decrease of roughly $11 \%$ and $28 \%$, for the $10 \%$ rPP and $15 \%$ rPP ratios, respectively.
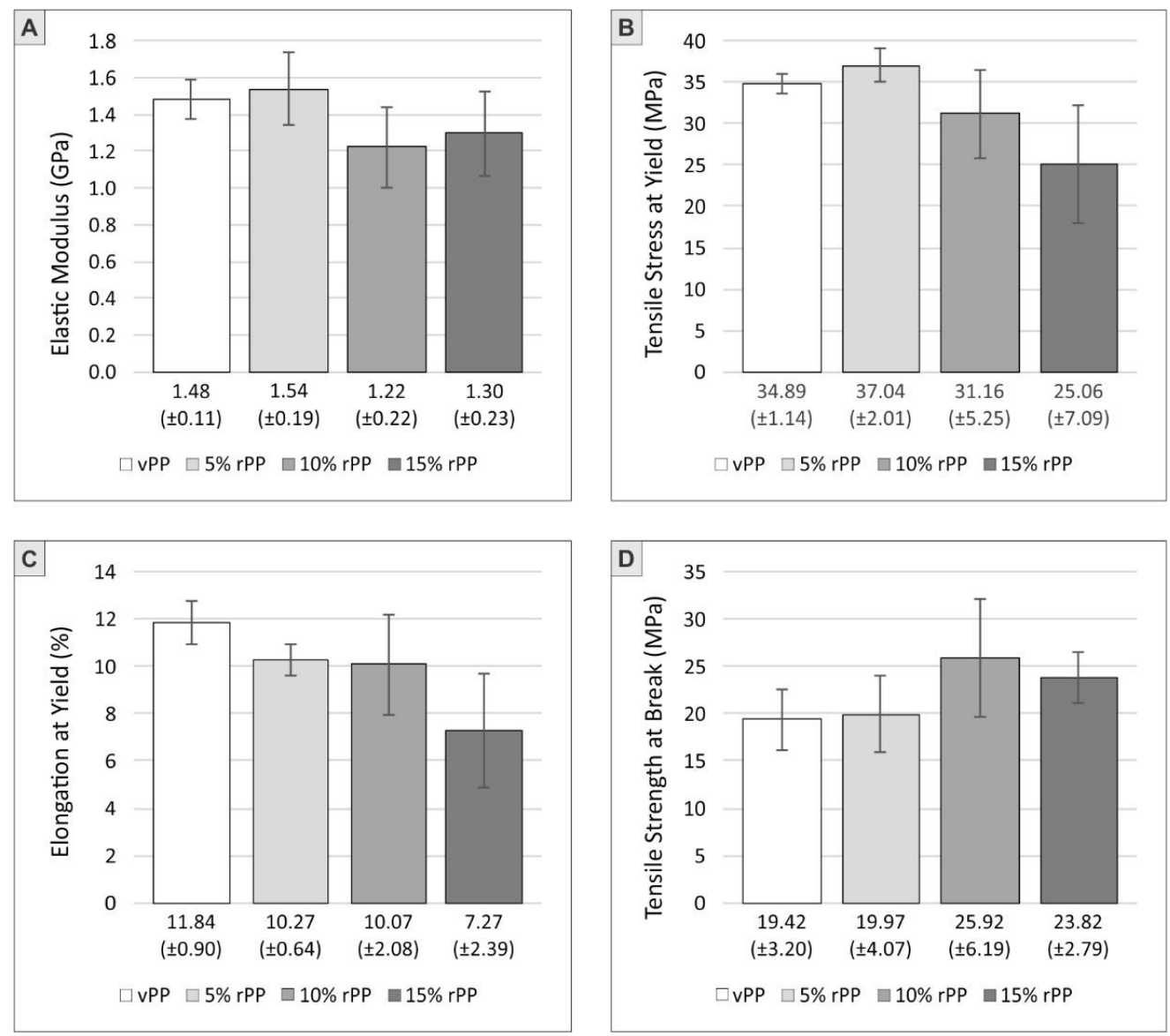

Fig. 3. Tensile tests results for mixture concentration of $5 \%(5 \% \mathrm{rPP}), 10 \%(10 \% \mathrm{rPP})$, and $15 \%(15 \% \mathrm{rPP})$ of recycled polypropylene samples, compared with virgin material (vPP) for: (A) elastic modulus, (B) tensile stress at yield, (C) elongation at yield, and (D) tensile strength at break. Values are given as average ( \pm std. dev).

The average elongation at yield (Fig. $3 \mathrm{C}$ ) of the $5 \% \mathrm{rPP}$ resulted in a decrease of approximately $13 \%$ compared to vPP. For the two other blend concentrations, 10\%rPP and 15\%rPP, the average elongation at yield decreased about $15 \%$ and $39 \%$, respectively. Similarly to the elastic modulus behavior, the lower molecular weight also contributes to lower elongation performance of recycled polypropylene (La Mantia 2002). Conversely, the tensile strength at break (Fig. 3D) resulted in similar average values for the VPP and the 5\%rPP, with a $3 \%$ performance increase by the later. As for the $10 \% \mathrm{rPP}$ and the $15 \% \mathrm{rPP}$, the average results were $33 \%$ and $23 \%$ higher, respectively. Due to higher average values of elastic modulus and tensile stress at yield, as well as lower results of elongation at yield, the increase of rPP concentration clearly indicates a more brittle performance.

The proximity of the resulted values for the elastic modulus, tensile stress at yield and at break of the vPP and the 5\%rPP make the content ratio of 5:95 a feasible choice for applications under the elastic regime; similar to results presented by Bhattacharya and Bepari, for recycled PP (2014). However, the same tests also resulted in an increase of $85 \%, 76 \%$, and $27 \%$ for each standard deviation (std. var.) value, respectively; with the exception of the 
elongation at yield, where the 5\%rPP presented a $29 \%$ lower std. var. compared with the VPP samples. Though, once dealing with a diversity of samples with multiple levels of degradation, higher std. var. values can be expected (Weinstein et al. 2016; Crawford and Quinn 2017b). As the degradation level of plastic debris in a marine environment is difficult to predict due to several possible variables (Avio et al. 2017), one should expect a higher variance in the results, mostly when applying simplified grinding and recycling methods (Scott 1999). In addition, the simplified recycling procedure, with manual grinding and content rationing of the mixture, could have contributed to higher std. var. values of rPP blended specimens. However, this simplified approach was followed in order to increase the feasibility of the process, on a larger scale.

An overall embrittlement can also be expected when reprocessing polymers such as PP due to loss of the polymer's elastic phase properties (Azapagic et al. 2003). Particularly, natural degradation is a common obstacle for the recycling of plastic debris found in marine environments (Crawford and Quinn 2017b). Thermal (Fayolle et al. 2000, 2002) and UV (Schoolenberg 1988; Schoolenberg and Vink 1991) oxidation, for instance, is the main responsible reasons for degradation and consequently the observed embrittlement of the analyzed blend specimens.

\subsection{Implications for the recovery of the marine plastics debris}

Although enclosed by a National Park and designated as an Environmental Protected Area, most literature about the Lençóis Maranhenses (LM) region and its related municipalities corresponds to economic (IBGE 2017), social (Barbosa et al. 2010; Barbosa 2015) or tourism (MTur 2014) data. The lack of information about the current environmental condition reflects on the little attention given to the presence of plastic debris nearby that region. This issue can be considered urgent on a holistic scale, as a result of (1) the direct impact of environmental contamination of plastics (Cole et al. 2011; Andrady 2017); (2) the consequences to the local economy due to impairment of the tourism industry (Sheavly and Register 2007; MTur 2014; Jang et al. 2014; Laglbauer et al. 2014); and (3) the resulting social issues on one of the country's poorest regions (Abakerli 2001; Barbosa 2015; IBGE 2017; Palombini et al. 2017). This research did not intend to map or classify the distribution of plastic debris on the entire LMNP coast, as well as to evaluate the economic feasibility of recycling micro- or mesoplastics, but to primarily disclose this issue as well as the multiple impacts caused by the lack of studies on that region. Therefore, we aimed to analyze and propose a possibility of recovering those small polymer particles, by means of simplified recycling method with polypropylene, one of the most abundant and degraded resins.

Due to the complexity of this issue, several measures need to be followed, from prevention to mitigation of plastics disposed in the marine environment (Ogunola et al. 2018). Sharma and Chatterjee (2017) list that introducing strong legislative rules, encouraging long-term monitoring research, increasing public awareness, compelling the use of biodegradable materials, as well as performing the recycling of plastic litters are measurements needed to address the problem at international, national and local levels.

Unfortunately, the literature on the recycling of small polymeric fragments from marine environments, such as macro- and microplastics, is still scarce, despite their recycling potential (Niaounakis 2017b). Pietrelli et al. (2017) performed a chemical and mechanical characterization of microplastic samples found on a pilot beach. Authors analyzed the recycling potential of PE samples, by mixing them with virgin resin, and suggested a recycling scheme for this type of debris. Even with the lack of data regarding the mechanical properties of recycled, marine polypropylene debris, environmental and economic benefits of common resin recycling can be raised. For instance, $\mathrm{Ha}$ (2012) and Kamleitner et al. (2017) presented the possibilities of reusing PP from post-consumer products, already considering the loss of mechanical properties from the process. Generally, authors reported that despite degradation, recycled material can be reused including in the manufacturing of new parts, with relatively satisfactory mechanical results, if the concentration limits in the mixture are weighted. In the same way, highimpact PP (Bahlouli et al. 2012; Kozderka et al. 2016) can also be recovered with appropriate content ratios. 
Moreover, there is the possibility of including recycled PP on composites (Izzati Zulkifli et al. 2015; Michalska-Pożoga et al. 2017) thus improving its life cycle. Despite fillers for the manufacturing of composites, by considering other resins such as PE, Pietrelli et al. (2017) also suggest the use of plasticizers to improve mechanical properties of microplastic debris. Therefore, the possibility of recovering marine plastic debris from Environmental Protected Areas, such as the LMNP, through recycling represents a significant advance.

Even though the accelerated degradation of polymers can be considered an interesting approach for reducing the amount of waste disposed on marine environments, such process can still take hundreds of years to complete, depending on the resin type (Crawford and Quinn 2017b). Furthermore, at the same time as large parts are decomposing, consequently, small particles are being released into the ecosystem. Not only light degradation on the surfaces of small plastic debris can occur, but the surface ablation mechanism into micron-sized particles is likely to happen (Andrady 2017). Weathering then leads to the harmfulness of secondary microplastics, including not only the direct physical impact of the injection of the particles but also the toxicity loading of persistent organic pollutants in the ingesting organism (Cole et al. 2011; Andrady 2017; Avio et al. 2017). Therefore, economic incentives should be applied to encourage practices that could not only avoid but remediate the marine litter problem (Niaounakis 2017b).

In addition to the rise of public awareness on the environmental contamination of plastic debris, Avio et al. (2017) highlight that stimulating new approaches to technological innovation for the reuse of these materials is of great importance. Likewise, Crawford and Quinn (2017b) state that recycling is an indispensable practice for reducing the amount of plastic waste on the environment. Although there are inherent difficulties related to collecting and sorting of polymeric waste from marine environments (Eerkes-Medrano et al. 2015; Van Cauwenberghe et al. 2015; Besley et al. 2017) for later recycling, this study presents a preliminary contribution for assessing the mechanical properties of a diversity of polypropylene sediment samples and consequently considering them for future applications.

\section{Conclusions}

This research presented the occurrence and a recovery analysis of small-sized plastic debris in the sediment nearby the Lençóis Maranhenses National Park (LMNP) coast, in northeast Brazil. Literature regarding recycling or recovering approaches of such debris on marine environments is still scarce, and focus mostly on disclosing, collecting, and sorting methods. It is clear that multiple degradation factors can induce the loss of mechanical performance of reprocessed small-sized plastic debris found in marine environments, particularly polypropylene. Therefore, a simplified recycling procedure was analyzed, using samples of this type resin, aiming to verify the recovery possibilities by mechanical testing.

We analyzed 88 plastic samples, collected on the sediment nearby LMNP, characterizing them by FT-IR. The results showed that most samples belong to commodities and, therefore, ubiquitous resins such as polypropylene (PP), high-density polyethylene (HDPE) and low-density polyethylene (LDPE). Due to a multifactorial degradation (e.g. thermal, UV light, abrasion, and biotic factors) in marine environments (Crawford and Quinn 2017b), PP samples were selected and used for a mechanical analysis on mixtures with $5 \%, 10 \%$ and $15 \%$ concentration ratios on virgin PP (VPP). The recycling procedure was carried out by means of a simplified approach, including manual grinding and weighted rationing of the mixture, in order to increase the feasibility of the process. The tensile test results suggest that at least a small concentration of $5 \%$ of marine recycled PP could be added on virgin PP, on polymer mixtures or composites, for the manufacturing of new parts. Despite the different and unpredictable levels of degradation of samples from the marine environment, an interesting performance is possible to obtain, mainly when working on the elastic regime. In addition, other types of less degraded resins could be assessed to verify their potential recovery by recycling. 
Despite not statistically collected, the sampling presented a similar relative counting to that estimated for the global plastic waste production, particularly related to commodity resins. Almost $90 \%$ of the collected samples were composed of the resins that represent $66 \%$ of global primary plastic production and $70 \%$ of waste generated, namely PP, HDPE, and LDPE (Plastics Europe 2016; Geyer et al. 2017). Thus, we suggest future works to focus on the recovery of such resins on marine environments, aiming to provide techniques and methods for recycling, as well as analyzing its feasibility in such degraded scenario.

The recovery of plastic debris from marine environments includes inherent difficulties and embraces different spheres. The LMNP region is considered one of the poorest in the country (Abakerli 2001; IBGE 2017), and its economy is greatly based on tourism from the park visitors (Castro and Piorski 2002; MTur 2014; Barbosa 2015). Therefore, besides direct harm to the ecosystem's environment, the presence of polymeric debris also leads to an impact on the economic and social spheres. In addition, besides cleaning the area, it is necessary to prevent newer debris from coming by the Atlantic (Costa et al. 2010; Graca et al. 2017). Hence, it is noteworthy that micro- mesoand macroplastic pollution on marine environments demands for both prevention and mitigation measures, embracing local, national, and global instances. Despite disclosing the occurrence of small plastic debris in the LMNP region, this paper aimed to show the positive effects recovery could deliver on a holistic sustainable approach, by reinserting such degraded polymers into a new cycle. Globally, the presence of plastic debris is of major concern due to several reasons, including in developed countries. Therefore, scientific research interest should be addressed on the plastic waste issue particularly in marine environments with poor economic scenarios, for example, the LMNP region, in ways to reduce or recover such pollution.

\section{Acknowledgments}

This study was supported by the National Council for Scientific and Technological Development (CNPq), the Foundation for Supporting Research of the State of Rio Grande do Sul (FAPERGS) and the Coordination of Higher Education Staff Improving (CAPES).

\section{References}

Abakerli S (2001) A critique of development and conservation policies in environmentally sensitive regions in Brazil. Geoforum 32:551-565. doi: 10.1016/S0016-7185(01)00015-X

Andrady AL (2011) Microplastics in the marine environment. Mar Pollut Bull 62:1596-1605. doi: 10.1016/j.marpolbul.2011.05.030

Andrady AL (2017) The plastic in microplastics: A review. Mar Pollut Bull 119:12-22. doi: 10.1016/j.marpolbul.2017.01.082

Avio CG, Gorbi S, Regoli F (2017) Plastics and microplastics in the oceans: From emerging pollutants to emerged threat. Mar Environ Res 128:2-11. doi: 10.1016/j.marenvres.2016.05.012

Azapagic A, Emsley A, Hamerton L (2003) Polymers, the Environment and Sustainable Development. John Wiley \& Sons, Ltd, Chichester, UK

Bahlouli N, Pessey D, Raveyre C, et al (2012) Recycling effects on the rheological and thermomechanical properties of polypropylene-based composites. Mater Des 33:451-458. doi: 10.1016/j.matdes.2011.04.049

Barbosa LGM (2015) Índice de competitividade do turismo nacional : relatório Brasil 2015. Brasilia

Barbosa LGM, Oliveira CTF de, Rezende C (2010) Competitiveness of tourist destinations: the study of 65 key destinations for the development of regional tourism. Rev Adm Pública 44:1067-1095. doi: 10.1590/S003476122010000500004

Begon M, Townsend CR, Harper JL (2006) Ecology : from individuals to ecosystems. Blackwell Pub

Besley A, Vijver MG, Behrens P, Bosker T (2017) A standardized method for sampling and extraction methods for quantifying microplastics in beach sand. Mar Pollut Bull 114:77-83. doi: 10.1016/j.marpolbul.2016.08.055

Bhattacharya D, Bepari B (2014) Feasibility study of recycled polypropylene through multi response optimization of injection moulding parameters using grey relational analysis. Procedia Eng 97:186-196. doi: 
10.1016/j.proeng.2014.12.241

Browne MA (2015) Sources and Pathways of Microplastics to Habitats. In: Marine Anthropogenic Litter. Springer International Publishing, Cham, pp 229-244

Cacciari I, Quatrini P, Zirletta G, et al (1993) Isotactic polypropylene biodegradation by a microbial community: physicochemical characterization of metabolites produced. Appl Environ Microbiol 59:3695-700

Castro ACL de, Piorski NM (2002) Plano de Manejo do Parque Nacional dos Lençóis Maranhenses. Brasilia

Cole M, Lindeque P, Halsband C, Galloway TS (2011) Microplastics as contaminants in the marine environment: A review. Mar Pollut Bull 62:2588-2597. doi: 10.1016/j.marpolbul.2011.09.025

Colling A V, Oliveira LB, Reis MM, et al (2016) Brazilian recycling potential: Energy consumption and Green House Gases reduction. Renew Sustain Energy Rev 59:544-549. doi: 10.1016/j.rser.2015.12.233

Costa MF, Ivar do Sul JA, Silva-Cavalcanti JS, et al (2010) On the importance of size of plastic fragments and pellets on the strandline: a snapshot of a Brazilian beach. Environ Monit Assess 168:299-304. doi: 10.1007/s10661009-1113-4

Crawford CB, Quinn B (2017a) The biological impacts and effects of contaminated microplastics. In: Microplastic Pollutants. Elsevier, pp 159-178

Crawford CB, Quinn B (2017b) Physiochemical properties and degradation. In: Microplastic Pollutants. Elsevier, pp 57-100

da Costa JP, Duarte AC, Rocha-Santos TAP (2017) Microplastics - Occurrence, Fate and Behaviour in the Environment. pp 1-24

Derraik JG. (2002) The pollution of the marine environment by plastic debris: a review. Mar Pollut Bull 44:842852. doi: 10.1016/S0025-326X(02)00220-5

Eerkes-Medrano D, Thompson RC, Aldridge DC (2015) Microplastics in freshwater systems: A review of the emerging threats, identification of knowledge gaps and prioritisation of research needs. Water Res 75:6382. doi: 10.1016/j.watres.2015.02.012

Eyerer P (ed) (2010) Polymers - Opportunities and Risks I. Springer Berlin Heidelberg, Berlin, Heidelberg

Fayolle B, Audouin L, Verdu J (2000) Oxidation induced embrittlement in polypropylene - a tensile testing study. Polym Degrad Stab 70:333-340. doi: 10.1016/S0141-3910(00)00108-7

Fayolle B, Audouin L, Verdu J (2002) Initial steps and embrittlement in the thermal oxidation of stabilised polypropylene films. Polym Degrad Stab 75:123-129. doi: 10.1016/S0141-3910(01)00211-7

Geyer R, Jambeck JR, Law KL (2017) Production, use, and fate of all plastics ever made. Sci Adv 3:e1700782. doi: 10.1126/sciadv.1700782

Gijsman P, Meijers G, Vitarelli G (1999) Comparison of the UV-degradation chemistry of polypropylene, polyethylene, polyamide 6 and polybutylene terephthalate. Polym Degrad Stab 65:433-441. doi: 10.1016/S0141-3910(99)00033-6

Graca B, Szewc K, Zakrzewska D, et al (2017) Sources and fate of microplastics in marine and beach sediments of the Southern Baltic Sea-a preliminary study. Environ Sci Pollut Res 24:7650-7661. doi: 10.1007/s11356017-8419-5

Gregory MR, Andrady AL (2004) Plastics in the Marine Environment. In: Plastics and the Environment. John Wiley \& Sons, Inc., Hoboken, NJ, USA, pp 379-401

Ha KH (2012) Open-loop recycling to apply refrigerator plastics from post-consumer waste polypropylene. Mater Des 35:310-317. doi: 10.1016/j.matdes.2011.09.062

Horton AA, Walton A, Spurgeon DJ, et al (2017) Microplastics in freshwater and terrestrial environments: Evaluating the current understanding to identify the knowledge gaps and future research priorities. Sci Total Environ 586:127-141. doi: 10.1016/j.scitotenv.2017.01.190

IBGE (2017) Barreirinhas: Expenditure, Revenue and GDP

Izzati Zulkifli N, Samat N, Anuar H, Zainuddin N (2015) Mechanical properties and failure modes of recycled polypropylene/microcrystalline cellulose composites. Mater Des 69:114-123. doi: 10.1016/j.matdes.2014.12.053

Janda K (2015) Petroleum Products. In: Handbook of Material Biodegradation, Biodeterioration, and Biostablization. Elsevier, pp 257-375

Jang YC, Hong S, Lee J, et al (2014) Estimation of lost tourism revenue in Geoje Island from the 2011 marine debris pollution event in South Korea. Mar Pollut Bull 81:49-54. doi: 10.1016/j.marpolbul.2014.02.021

Kamleitner F, Duscher B, Koch T, et al (2017) Long chain branching as an innovative up-cycling process of polypropylene post-consumer waste - Possibilities and limitations. Waste Manag. doi: 10.1016/j.wasman.2017.07.022 
Koelmans AA, Gouin T, Thompson R, et al (2014) Plastics in the marine environment. Environ Toxicol Chem 33:510. doi: 10.1002/etc.2426

2

Kozderka M, Rose B, Kočí V, et al (2016) High impact polypropylene (HIPP) recycling - Mechanical resistance and Lifecycle Assessment (LCA) case study with improved efficiency by preliminary sensitivity analysis. J Clean Prod 137:1004-1017. doi: 10.1016/j.jclepro.2016.07.217

La Mantia FP (2002) Handbook of plastics recycling. Rapra Technology Ltd, Shrewsbury

Laglbauer BJL, Franco-Santos RM, Andreu-Cazenave M, et al (2014) Macrodebris and microplastics from beaches in Slovenia. Mar Pollut Bull 89:356-366. doi: 10.1016/j.marpolbul.2014.09.036

Law KL, Thompson RC (2014) Microplastics in the seas. Science (80- ) 345:144-145. doi: 10.1126/science.1254065

Mai L, Bao L-J, Shi L, et al (2018) A review of methods for measuring microplastics in aquatic environments. Environ Sci Pollut Res. doi: 10.1007/s11356-018-1692-0

Marsich L, Ferluga A, Cozzarini L, et al (2017) The effect of artificial weathering on PP coextruded tape and laminate. Compos Part A Appl Sci Manuf 95:370-376. doi: 10.1016/j.compositesa.2017.01.016

Medeiros R, Young CEF (eds) (2011) Contribuição das unidades de conservação brasileiras para a economia nacional: Relatório Final. UNEP-WCMC, Brasília

Michalska-Pożoga I, Rydzkowski T, Mazur P, et al (2017) A study on the thermodynamic changes in the mixture of polypropylene (PP) with varying contents of technological and post-user recyclates for sustainable nanocomposites. Vacuum. doi: 10.1016/j.vacuum.2017.05.027

MSFD GES Technical Subgroup on Marine Litter (2013) Monitoring Guidance for Marine Litter in European Seas, Draft Report. European Commission, Brussels

MTur (2014) Plano Estratégico de Desenvolvimento do Turismo Regional da Rota das Emoções. São Paulo

Muenmee S, Chiemchaisri W, Chiemchaisri C (2015) Microbial consortium involving biological methane oxidation in relation to the biodegradation of waste plastics in a solid waste disposal open dump site. Int Biodeterior Biodegradation 102:172-181. doi: 10.1016/j.ibiod.2015.03.015

Niaounakis M (2017a) Degradation of Plastics in the Marine Environment. In: Management of Marine Plastic Debris. Elsevier, pp 127-142

Niaounakis M (2017b) Management of Marine Plastic Debris : prevention, recycling, and waste management. William Andrew, Kidlington, Oxford

Ogunola OS, Onada OA, Falaye AE (2018) Mitigation measures to avert the impacts of plastics and microplastics in the marine environment (a review). Environ Sci Pollut Res. doi: 10.1007/s11356-018-1499-z

Palombini FL, Cidade MK, de Jacques JJ (2017) How sustainable is organic packaging? A design method for recyclability assessment via a social perspective: A case study of Porto Alegre city (Brazil). J Clean Prod 142:2593-2605. doi: 10.1016/j.jclepro.2016.11.016

Pietrelli L, Poeta G, Battisti C, Sighicelli M (2017) Characterization of plastic beach debris finalized to its removal: a proposal for a recycling scheme. Environ Sci Pollut Res 24:16536-16542. doi: 10.1007/s11356-017-9440-4

Plastics Europe (2016) Plastics - The Facts 2016 : An analysis of European latest plastics production, demand and waste data. 38

PlasticsEurope (2016) Plastics - The Facts 2016 : An analysis of European plastics production, demand and waste data. PlasticsEurope, Brussels

Schoolenberg GE (1988) A fracture mechanics approach to the effects of UV-degradation on polypropylene. J Mater Sci 23:1580-1590. doi: 10.1007/BF01115695

Schoolenberg GE, Vink P (1991) Ultra-violet degradation of polypropylene: 1. Degradation profile and thickness of the embrittled surface layer. Polymer (Guildf) 32:432-437. doi: 10.1016/0032-3861(91)90446-P

Scott G (1999) Polymers and the Environment. Royal Society of Chemistry, Cambridge, UK

Sharma S, Chatterjee S (2017) Microplastic pollution, a threat to marine ecosystem and human health: a short review. Environ Sci Pollut Res 24:21530-21547. doi: 10.1007/s11356-017-9910-8

Sheavly SB, Register KM (2007) Marine debris and plastics: environmental concerns, sources, impacts and solutions. J Polym Environ 15:301-305. doi: 10.1007/s10924-007-0074-3

Tanaka K, Takada H, Yamashita R, et al (2013) Accumulation of plastic-derived chemicals in tissues of seabirds ingesting marine plastics. Mar Pollut Bull 69:219-222. doi: 10.1016/j.marpolbul.2012.12.010

Thompson RC, Moore CJ, vom Saal FS, Swan SH (2009) Plastics, the environment and human health: current consensus and future trends. Philos Trans R Soc B Biol Sci 364:2153-2166. doi: 10.1098/rstb.2009.0053

US Environmental Protection Agency (2016) Advancing Sustainable Materials Management: 2014 Fact Sheet. Washington

Van Cauwenberghe L, Devriese L, Galgani F, et al (2015) Microplastics in sediments: A review of techniques, 
occurrence and effects. Mar Environ Res 111:5-17. doi: 10.1016/j.marenvres.2015.06.007

Weinstein JE, Crocker BK, Gray AD (2016) From macroplastic to microplastic: Degradation of high-density polyethylene, polypropylene, and polystyrene in a salt marsh habitat. Environ Toxicol Chem 35:1632-1640. doi: $10.1002 /$ etc.3432 